Artigo de Revisão

\title{
Progressos na imunização contra Anaplasma marginale ${ }^{1}$
}

\author{
Flábio R. Araúijo ${ }^{2 *}$, Cláudio R. Madruga² ${ }^{2}$ Cleber O. Soares ${ }^{2}$ e Raul H. Kessler ${ }^{2}$
}

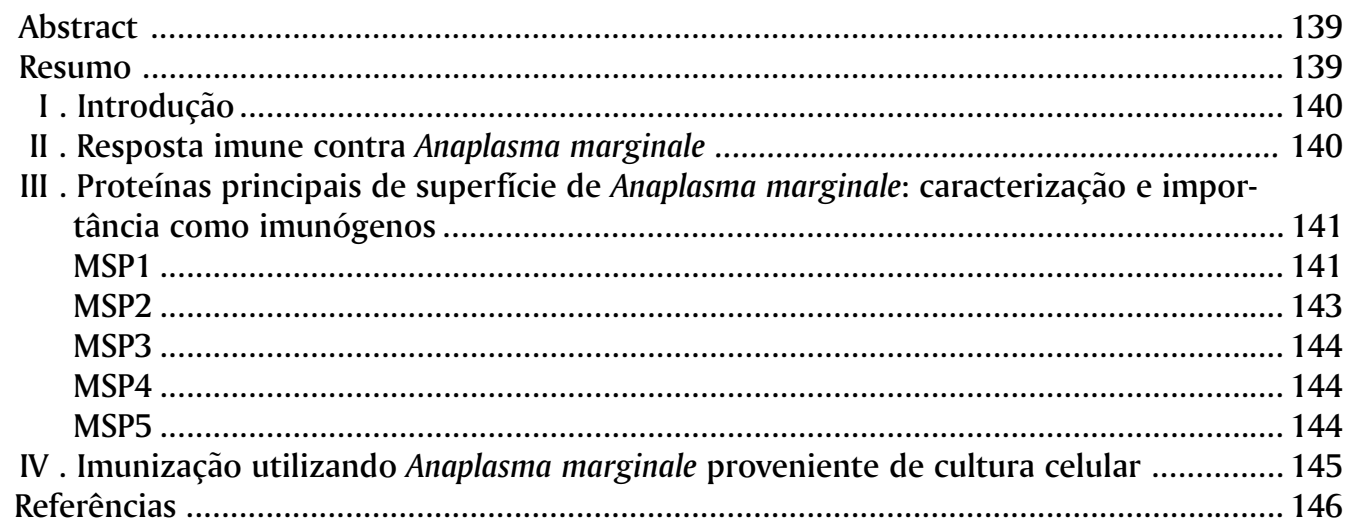

ABSTRACT.- Araújo F.R., Madruga C.R., Soares C.O. \& Kessler R.H. 2003. [Progresses in immunization against Anaplasma marginale.] Progressos na imunização contra Anaplasma marginale. Pesquisa Veterinária Brasileira 23(3):139-148. Embrapa Gado de Corte, Cx. Postal 154, Campo Grande, MS 79002-970, Brazil. E-mail: flabio@cnpgc.embrapa.br

The current immunization against anaplasmosis in cattle is derived from the blood of infected animals, as live or dead organisms. Nevertheless, efforts have been made to develop a new generation of vaccines. The outer membrane of Anaplasma marginale induces a protective immune response against challenge with homologous isolates and a partially protective response against heterologous challenge. In this membrane, six major surface proteins (MSPs) have been identified, which have been targeted for the development of immunogens against anaplasmosis. From those proteins, MSP1a and MSP2 have shown the greatest potential as immunogens, protecting cattle against challenge with virulent homologous and heterologous isolates of $A$. marginale, despite the size polymorphism of the former protein and the variability of the gene that encodes the latter protein. Another alternative of immunogen is the in vitro culture of $A$. marginale. Inactivated organisms originating from Dermacentor variabilis IDE8 cell culture were tested as immunogen. Cattle immunized with cell culture-derived $A$. marginale had a significantly lower reduction in the packed cell volume after challenge exposure and did not display clinical anaplasmosis. Besides the protection afforded by this type of immunogen, cell culture derived organisms are free from bovine cells and pathogens, what is a major advantage as compared with traditional immunization procedures.

INDEX TERMS: Anaplasma marginale, Ehrlichiae, immunization, bovine, major surface proteins, culture.

${ }^{1}$ Recebido em 7 de janeiro de 2003.

Aceito para publicação em 21 de abril de 2003.

${ }^{2}$ Embrapa Gado de Corte, BR-264 Km 4, Caixa Postal 154, Campo Grande, MS 79002-970, Brasil. *Autor para correspondência. E-mail: flabio@cnpgc.embrapa.br
RESUMO.- Até o presente momento, as imunizações contra anaplasmose em rebanhos bovinos utilizam organismos vivos ou mortos. No entanto, esforços têm sido realizados nos últimos anos com o objetivo de desenvolver uma nova geração de vacinas. A membrana externa de Anaplasma marginale 
é capaz de induzir reposta imune protetora contra desafio homólogo e parcialmente protetora contra desafio heterólogo. Nela foram identificadas seis proteínas principais de superfície (MSPs), as quais têm sido alvo de estudos para o desenvolvimento de imunógenos contra a anaplasmose. Destas proteínas, MSP1a e MSP2 têm demonstrado maior potencial como imunógenos, protegendo os animais contra desafio com isolados virulentos homólogos e heterólogos de $A$. marginale, apesar do polimorfismo de tamanho da primeira proteína e variabilidade do gene que codifica a segunda. Uma outra alternativa para a imunização contra $A$. marginale é o cultivo in vitro dessa riquétsia. Organismos inativados provenientes de cultivo em células IDE8 de Dermacentor variabilis foram testados como imunógeno. Os animais apresentaram uma significativa diferença na redução do volume globular após desafio e não apresentaram sinais clínicos de anaplasmose. Além da proteção conferida por este tipo de imunógeno, os organismos provenientes de cultura de células de carrapato são livres de células e patógenos de bovinos, o que é uma vantagem significativa quando comparado aos processos tradicionais de imunização.

TERMOS DE INDEXAÇÃO: Anaplasma marginale, Ehrlichiae, imunização, bovino, proteínas principais de superfície, cultura.

\section{INTRODUÇÃO}

A anaplasmose é uma doença de bovinos e ruminantes silvestres, causada pela riquétsia intra-eritrocítica Anaplasma marginale. Este microrganismo está disseminado em várias partes do mundo, e causa importantes perdas econômicas, sobretudo em áreas tropicais e subtropicais (Eriks et al. 1993, Gale et al. 1997).

A transmissão dessa riquétsia é feita por carrapatos, dípteros hematófagos e por fômites contaminados (Barbet 1995). A fase aguda da anaplasmose é caracterizada por altas riquetsemias $\left(>10^{9}\right.$ eritrócitos infectados por $\left.\mathrm{mL}\right)$, anemia, perda de peso, aborto, e até morte (Alleman et al. 1997). Os animais que sobrevivem a esta fase permanecem persistentemente infectados, com baixas riquetsemias, não detectáveis microscopicamente $\left(<10^{7}\right.$ eritrócitos infectados por $\left.\mathrm{mL}\right)$, e servem como reservatórios para transmissão (Zaugg et al. 1986, Eriks et al. 1993).

A anaplasmose é particularmente importante nas regiões de instabilidade enzoótica, nas quais há uma grande percentagem de animais susceptíveis à infecção por $A$. marginale. Nesta situação, a maioria dos animais não se infecta nos primeiros meses de vida, quando são menos susceptíveis a essa infecção (Madruga et al. 1985). Em áreas de estabilidade enzoótica, populações de animais que são introduzidos provenientes de áreas livres de carrapato ou de rebanhos sob controle intensivo de carrapatos e bezerros na faixa etária de 30 a 120 dias com baixa imunidade apresentam risco de anaplasmose (Madruga et al. 1984).

O controle da anaplasmose é realizado por quimioterapia, controle de vetores e imunização, sendo esse último mais eficiente (Palmer 1989).

A maioria das imunizações é realizada com organismos vivos. Apesar da existência de $A$. marginale atenuado (Ristic 1979), A. marginale virulento (premunição) e Anaplasma centrale, espécie considerada menos patogênica, são os mais empregados na vacinação de bovinos na América Latina (Kessler \& Schenk 1998). Na América do Norte, organismos mortos de $A$. marginale também têm sido utilizados para imunização. Apesar do satisfatório grau de imunidade induzida por esses antígenos, os mesmos apresentam limitações. Com relação às vacinas vivas, existe o risco de causar manifestações clínicas de anaplasmose em bovinos adultos, particularmente em vacas prenhes, enquanto que os antígenos mortos podem causar isoeritrólise neonatal, devido à sensibilização de vacas para grupos sangüíneos (Rogers et al. 1988). Ademais, ambos sistemas de vacinação constituem fontes potenciais de contaminação do animal imunizado com microrganismos veiculados pelo sangue (Kessler \& Schenk 1998).

A membrana externa de $A$. marginale é capaz de induzir reposta imune protetora contra desafio homólogo e parcialmente protetora contra desafio heterólogo (Tebele \& Palmer 1991, Tebele et al. 1991). Nela foram identificadas seis proteínas principais de superfície - MSPs (Palmer \& McGuire 1984, Tebele et al. 1991), as quais têm sido alvo de estudos para o desenvolvimento de imunógenos contra a anaplasmose.

Até o presente momento, portanto, as imunizações contra anaplasmose em rebanhos bovinos utilizam organismos vivos ou mortos. Esforços têm sido realizados nos últimos anos com o objetivo de desenvolver uma nova geração de vacinas que supere os problemas mencionados anteriormente. Desta forma, é apresentada uma revisão sobre antígenos potenciais, particularmente sobre MSPs, e das estratégias de direcionamento e potencialização da resposta imune contra essas proteínas.

\section{RESPOSTA IMUNE CONTRA Anaplasma marginale}

A imunidade contra $A$. marginale requer mecanismos humorais e celulares. Anticorpos direcionados contra corpúsculos iniciais bloqueiam a infectividade da riquétsia (Palmer \& McGuire 1984). Na membrana desses corpúsculos foram identificadas proteínas principais de superfície (major surface proteins MSPs) (Palmer \& McGuire 1984, Tebele et al. 1991), as quais induzem a produção de anticorpos que estão correlacionados com o controle da riquetsemia aguda e anemia (Tebele et al. 1991). Possivelmente, anticorpos contra MSPs funcionam como opsoninas, facilitando a fagocitose e a eliminação de A. marginale por macrófagos. Tal função já foi demonstrada em ensaios in vitro com anticorpos de bovinos imunizados com MSP1 (Cantor et al. 1993). Outra possível função dos anticorpos seria o bloqueio da invasão de eritrócitos pela riquétsia. Anticorpos contra MSP1 bloqueiam a aglutinação de eritrócitos de bovinos por corpúsculos iniciais de $A$. marginale (McGarey \& Allred 1994).

Apesar da importância dos anticorpos na imunidade contra $A$. marginale, é pouco provável que, isoladamente, os mesmos sejam capazes de proteger os bovinos contra a anaplasmose (Brown et al. 2001b), uma vez que a inoculação 


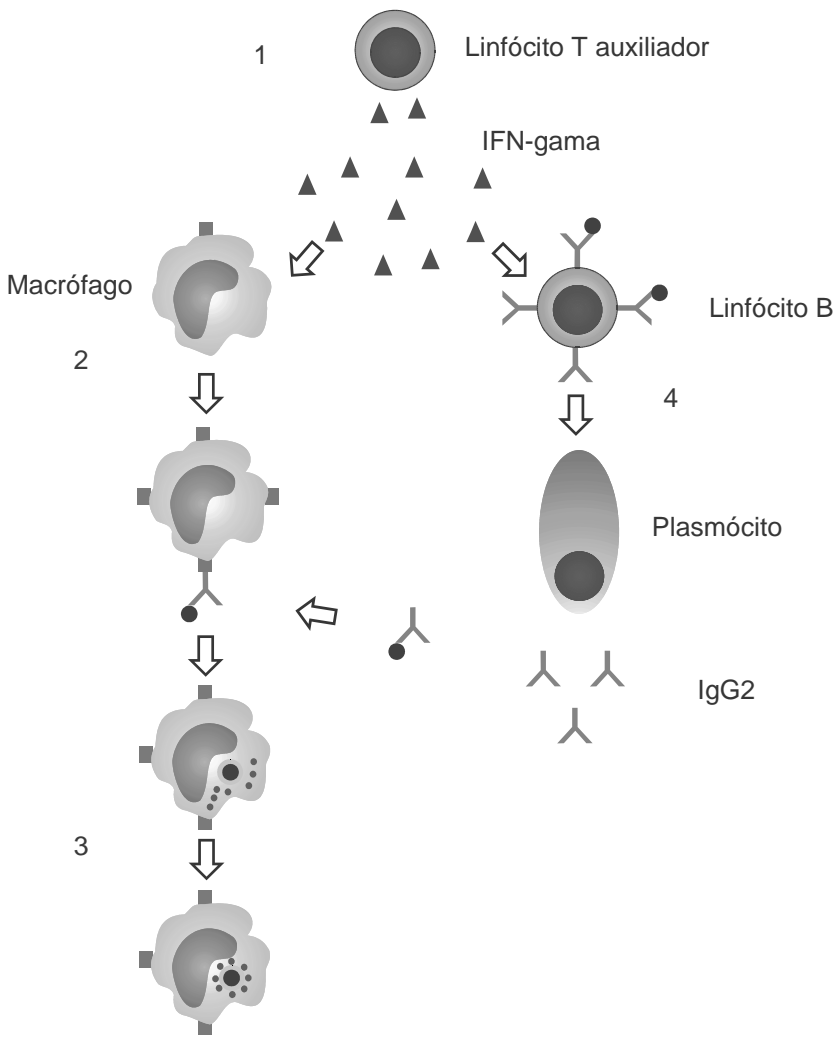

Fig. 1. Modelo de resposta imune celular e humoral contra Anaplasma marginale.

a. Linfócitos T auxiliadores (CD4 $\left.{ }^{+}\right)$, estimulados por antígenos de $A$. marginale, produzem interferon-g (IFN-g), o qual atua sobre macrófagos e linfócitos $B$.

b. Sobre macrófagos, o IFN-g estimula a expressão de receptores de Fc, facilitando a fagocitose de $A$. marginale.

c. Atua também aumentando a fusão fagossomo-lisossomo e a produção de óxido nítrico, resultando na destruição intracelular de A. marginale.

d. O IFN-g estimula a produção de $\lg G_{2}$ por linfócitos $B$. Esse isotipo tem importante função na opsonização de $A$. marginale para a fagocitose.

de soro de animais imunes em bovinos susceptíveis não protege contra desafio com A. marginale (Gale et al. 1992). Dessa forma, evidencia-se a importância das repostas celulares, as quais envolvem a participação de linfócitos $\mathrm{T}$ auxiliadores $\left(\mathrm{CD}^{+}\right)$, produtores de interferon-g (IFN-g) (Brown et al. 1998a). Essa citocina ativa macrófagos, aumentando a produção de óxido nítrico (NO), substância que têm ação tóxica sobre riquétsias; estimulando a expressão de receptores de Fc e a fusão de fagossomos e lisossomos (Brown et al. 1998a) (Fig. 1). Além disso, demonstrou-se que, em bovinos, o IFN-g atua sobre linfócitos $B$, estimulando a produção de $\operatorname{IgG}_{2}$ (Estes et al. 1994). Esse isotipo apresenta maior capacidade de promover fagocitose por meio de opsonização do que a $\operatorname{lgG}_{1}$ (McGuire et al. 1979), estando provavelmente envolvido no processo de neutralização da infectividade de corpúsculos iniciais de $A$. marginale mediada por anticorpos (Tuo et al. 2000).
Valdez et al. (2002) investigaram o papel in vivo de linfócitos $\mathrm{T} \mathrm{CD}^{+}$durante a anaplasmose aguda, mediante a depleção parcial dessas células com anticorpo monoclonal anti-CD4 em bezerros timectomizados, os quais foram infectados posteriormente com isolado da Flórida de A. marginale. Os autores não verificaram diferenças estatisticamente significativas quanto ao decréscimo do volume globular nem riquetsemia com relação ao grupo controle.

Apesar dos animais tratados com anti-CD4 terem controlado a infecção por $A$. marginale, as conclusões sobre o papel dos linfócitos $\mathrm{T} \mathrm{CD}^{+}$na resposta imune contra a riquétsia foram prejudicadas em função dos autores não terem conseguido depleção completa destas células (Valdez et al. 2002). No entanto, alguns aspectos interessantes puderam ser observados. Em um dos experimentos, os animais tratados com anti-CD4 tiveram níveis quatro a seis vezes inferiores de $\operatorname{IgG}_{1}$ com relação ao grupo controle e ausência de $\lg G_{2}$, ambas específicas para MSP2, o que sugere que não há necessidade de altos títulos destas subclasses de anticorpos para o controle da infecção por $A$. marginale.

Outro fator que merece atenção é o papel das células $\mathrm{T}$ gd no controle da infecção por $A$. marginale. No experimento conduzido por Valdez et al. (2002), verificou-se uma expansão progressiva destas células no sangue periférico e baço dos animais infectados. Sabe-se que estas células representam até $75 \%$ dos linfócitos T em bezerros (Wyatt et al. 1994), os quais, apesar de serem susceptíveis à infecção por $A$. marginale, são mais resistentes ao desenvolvimento de alterações clínicas do que os animais adultos (Jones et al. 1968). Ademais, demonstrou-se que linfócitos gd são capazes de lisar células infectadas com Theileria parva de maneira não restrita a antígenos do complexo de histocompatibilidade principal (MHC) (Daubenberger et al. 1999).

\section{PROTEÍNAS PRINCIPAIS DE SUPERFÍCIE DE Anaplasma marginale: CARACTERIZAÇÃO E IMPORTÂNCIA COMO IMUNÓGENOS}

As pesquisas voltadas para o desenvolvimento de vacinas mais eficazes e seguras estão focalizadas nas proteínas de membrana dos corpúsculos iniciais de $A$. marginale. Essas proteínas são expostas na superfície da riquétsia, sendo facilmente acessíveis ao sistema imunológico do hospedeiro. Também desempenham importantes funções para a sobrevivência do parasito (Arulkanthan et al. 1999), tais como aderência e invasão dos eritrócitos do hospedeiro e transporte de nutrientes (McGarey et al. 1994, Fuente et al. 2001a).

Na membrana dos corpúsculos iniciais de $A$. marginale foram identificadas seis proteínas principais de superfície: MSP1a (105 kDa), MSP1b (100 kDa), MSP2 (36 kDa), MSP3 (86 kDa), MSP4 (31 kDa) e MSP5 (19 kDa) (Palmer \& McGuire 1984, Barbet et al. 1987, Oberle et al. 1988, Tebele et al. 1991, Oberle et al. 1993).

\section{MSP1}

A MSP1 é um complexo de duas proteínas, com massas moleculares de 105 e 100 kDa, denominadas MSP1a e MSP1b, 


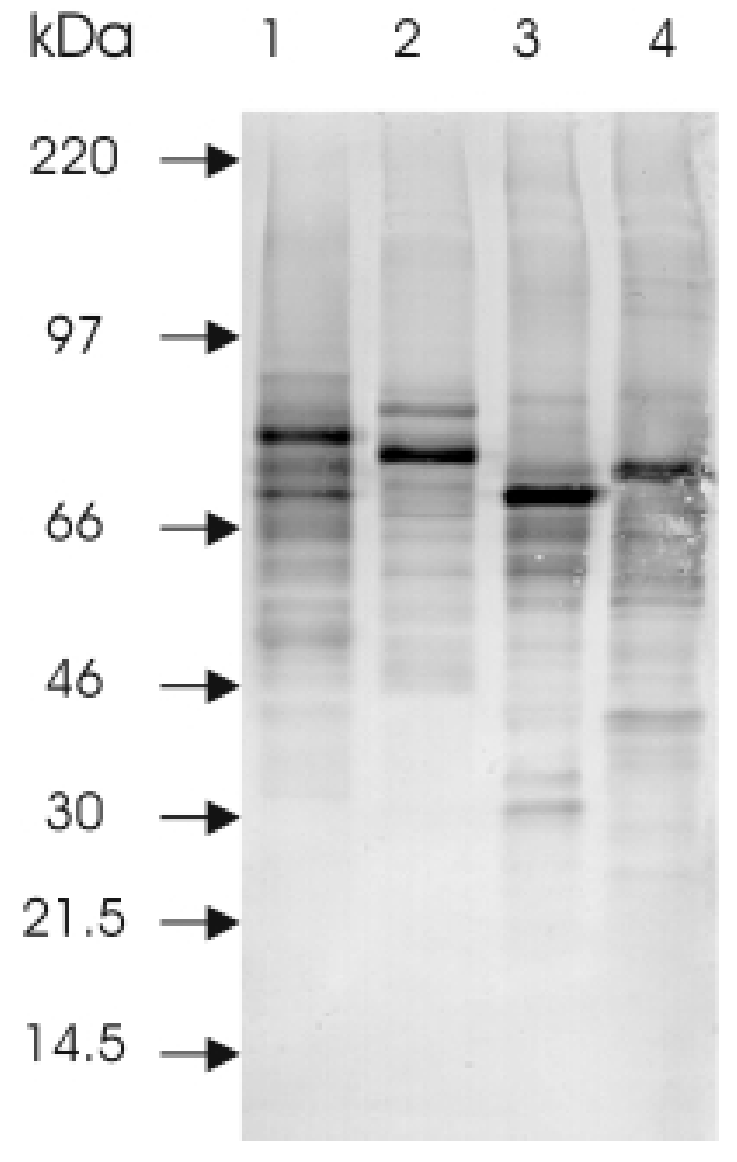

Fig. 2. Western blot com antígenos de isolados brasileiros de Anaplasma marginale e anticorpo monoclonal ANA22B1: linha 1, Pernambuco-Zona da Mata; linha 2, Pernambuco, Agreste; linha 3, Pernambuco, Sertão; linha 4, Mato Grosso do Sul, Campo Grande. (Oliveira et al. 2003)

respectivamente (Barbet et al. 1987, Oberle et al. 1988). Uma única proteína MSP1a está ligada covalentemente, por pontes dissulfeto, a proteínas MSP1b (Vidotto et al. 1994).

A MSP1a é codificada por um único gene (msp1a), porém possui marcante variação de tamanho entre os diferentes isolados de $A$. marginale (46 a $105 \mathrm{kDa}$ ), como verificado em isolados brasileiros desta riquétsia (Kano et al. 2002, Oliveira et al. 2003) (Fig. 2). Isso resulta da presença de um número variável de blocos repetitivos de 28 a 29 aminoácidos, ricos em serina, na região amino $(\mathrm{N})$ terminal (Oberle et al. 1988, Allred et al. 1990). Essa região contém um epitopo sensível à neutralização conservado entre os isolados (Palmer et al. 1987, Allred et al. 1990), incluindo brasileiros (Kano et al. 2002, Oliveira et al. 2003) o qual é reconhecido pelos anticorpos monoclonais ANA22B1 e ANA15D2 (McGuire et al. 1984, Allred et al. 1990).

A amplificação por reação da polimerase em cadeia (PCR) (Lew et al. 2002) e o sequenciamento da porção repetitiva do gene msp1a (Fuente et al. 2002a) permitiram respectivamente a comparação filogeográfica de diferentes isolados australianos de $A$. marginale e do Novo Mundo.
A MSP1b é codificada por uma família multigênica (Barbet \& Allred 1991), porém possui polimorfismo mínimo de tamanho entre isolados (cerca de $3 \mathrm{kDa}$ ) (Oberle et al. 1988). Esta família gênica foi clonada e seqüenciada a partir do isolado da Flórida de $A$. marginale e dois genes foram identificados e denominados msp1b1 e msp1b2 (Viseshakul et al. 2000). Posteriormente, trabalhando com o mesmo isolado, CamachoNuez et al. (2000) não identificaram o gene msp1b2, porém caracterizaram mais três genes. Recentemente, Bowie et al. (2002) confirmaram os achados de Viseshakul et al. (2000), tendo encontrado apenas os genes $m s p 1 \mathrm{~b} 1$ e $m s p 1 \mathrm{~b} 2$, os quais foram conservados entre os isolados da Flórida e de Oklahoma. Os genes apresentaram uma similaridade entre isolados, em termos de sequiência preditiva de aminoácidos, de $96 \%$ para MSP1b1 e $92 \%$ para MSP1b2, o que sugere que as regiões altamente conservadas dessa proteína podem ter importância como imunógenos.

Bowie et al. (2002) sugeriram que os diferentes genes encontrados por Camacho-Nuez et al. (2000) na verdade seriam mosaicos de $m s p 1 \mathrm{~b} 1$ e $m s p 1 \mathrm{~b} 2$, que representariam seqüências polimórficas de menor expressão na população de $A$. marginale.

A imunização de bovinos com a MSP1 nativa protegeu os animais contra desafio com isolado virulento homólogo de A. marginale (Palmer et al. 1986a). Posteriormente, verificouse que a imunização com MSP1 também protegeu bovinos contra desafio com isolado heterólogo (Palmer et al. 1989). Tais resultados demonstraram que, apesar da marcante variação de tamanho da MSP1a entre os diferentes isolados, epitopos da MSP1 relevantes para proteção cruzada estão conservados entre os isolados (Palmer et al. 1989).

Experimentos conduzidos com MSP1a e MSP1b demonstraram que a imunização com essas proteínas recombinantes, utilizadas isoladamente ou em conjunto, não induziram proteção no mesmo nível que a MSP1 nativa (Palmer \& McElwain 1995). Uma possível explicação para esse fato seria a ausência de associação covalente entre as mesmas (Brown et al. 2001b).

As funções da MSP1 são parcialmente conhecidas. Sabese que MSP1a e MSP1b atuam como adesinas (McGarey et al. 1994), estando envolvidas no processo de invasão dos corpúsculos iniciais de $A$. marginale à membrana dos eritrócitos do hospedeiro. Verificou-se também que a MSP1a é uma adesina para células de carrapato (Fuente et al. 2001a), influenciando na transmissão de $A$. marginale por esse artrópode. Carrapatos Dermacentor variabilis foram capazes de transmitir o isolado de Oklahoma dessa riquétsia, porém não transmitiram o isolado da Flórida (Fuente et al. 2001b). Nesse estudo, constatou-se ainda que a MSP1 do isolado da Flórida de $A$. marginale não foi capaz de mediar aderência às células intestinais dos carrapatos, inibindo, portanto, a posterior infecção da glândula salivar e transmissão para os bovinos.

A imunidade protetora em bovinos imunizados com MSP1 nativa está associada com respostas humorais. Anticorpos contra MSP1, MSP1a ou MSP1b inibem a ligação de $A$. marginale aos eritrócitos, o que sugere que os mesmos desenvolvem uma atividade neutralizante da invasão da riquétsia 
às células do hospedeiro (McGarey \& Allred 1994, McGarey et al. 1994).

Soros de bovinos imunizados com MSP1 nativa reconheceram a MSP1a e a MSP1b, não havendo diferenças significativas nos títulos de anticorpos contra as duas proteínas. A classe de anticorpo predominantemente direcionada contra a MSP1 é a IgG (Brown et al. 2001b). Na MSP1a, são reconhecidos epitopos na região carboxi $(C)$ terminal e na região $\mathrm{N}$ terminal (Brown et al. 2001b). Essa última região contém o epitopo B EASTS(S/Q)ASTSS sensível à neutralização (Allred et al. 1990). Motivos conservados ricos em serina também foram descritos em unidades protéicas repetitivas de alta massa molecular do agente da ehrlichiose granulocítica humana, Ehrlichia phagocytophila, recentemente reclassificada como Anaplasma phagocytophila (Dumler et al. 2001), Ehrlichia canis e Ehrlichia chaffeensis (Yu et al. 1997, Storey et al. 1998, McBride et al. 2000, Yu et al. 2000). Acredita-se que esses motivos são sítios para uma forma distinta de glicosilação (McBride et al. 2000) ligada a resíduos 0, o que explicaria o fato de que, para um determinado isolado, a massa molecular da MSP1, separada em géis de poliacrilamida, é maior do que o esperado, por meio da análise de sua seqüência (Allred et al. 1990). Até o momento, não se sabe se a MSP1a é glicosilada e qual a importância que essa glicosilação teria na neutralização da infectividade por anticorpos.

A participação de células $\mathrm{T} \mathrm{CD}^{+}$na imunidade contra MSP1 também foi avaliada. Células mononucleares de sangue periférico e células $\mathrm{T} \mathrm{CD}^{+}$de bovinos imunizados com MSP1 proliferaram intensamente em resposta a isolado homólogo e heterólogo de $A$. marginale. Analisando-se a participação da MSP1a e MSP1b nessas respostas, verificou-se que os epitopos $\mathrm{T}$ conservados estavam localizados na região C terminal da MSP1-a, a qual estimulou altos níveis de IFN-g. Houve fraca ou nenhuma resposta celular contra MSP1b. Em contraste, houve uma forte resposta humoral contra MSP1a e MSP1b (Brown et al. 2001b). Esses fatos sugerem que na resposta imune contra MSP1, linfócitos $\mathrm{T}$ específicos para MSP1a funcionam como células auxiliadoras para linfócitos B específicos para MSP1b. Estudos mais detalhados visando identificar os epitopos T da MSP1a e os epitopos B da MSP1a e MSP1b são necessários para o desenvolvimento de vacinas contra $A$. marginale (Brown et al. 2001b).

MSP2

A MSP2 é uma proteína imunodominante de superfície, codificada por uma família de genes polimórficos (Palmer et al. 1994a). Ocorre como monômeros ou multímeros, ligados por pontes dissulfeto (Vidotto et al. 1994).

A análise dos diversos transcritos que codificam a MSP2 mostraram uma região central hipervariável única flanqueada por regiões $\mathrm{N}$ e $\mathrm{C}$ terminais altamente conservadas. Estrutura semelhante também foi identificada em $A$. phagocytophila, com homologia nas regiões $\mathrm{N}$ e $\mathrm{C}$ terminais de 96 e $87 \%$, respectivamente (French et al. 1999). Isso sugere que as proteínas de ambos os microrganismos desempenham funções semelhantes e são importantes para a sobrevivência dos mesmos (Brown et al. 2001a).

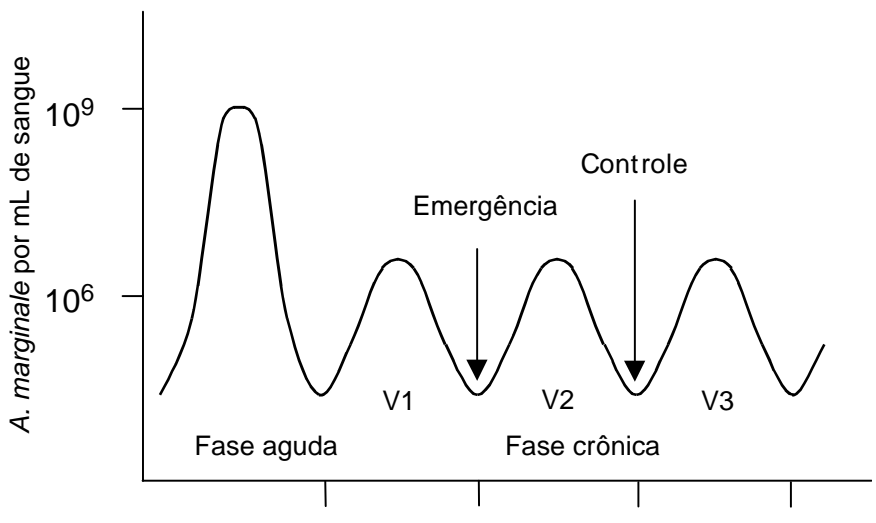

Semanas pós-infecção

Fig. 3. Variação antigênica de Anaplasma marginale. Os altos níveis de riquetsemia por $A$. marginale na fase aguda da infecção são resolvidos após o desenvolvimento de uma resposta imune primária. No entanto, a emergência de variantes antigênicas (V) resulta em infecção persistente, a qual é caracterizada por ciclos de riquetsemia, aproximadamente a cada cinco semanas. Nesses ciclos, novas variantes expressando MSP2 distintas replicam, alcançando picos de $>10^{6}$ organismos por $\mathrm{mL}$ de sangue, os quais são controlados por nova resposta imune específica (adaptado de Palmer et al. 1999).

Durante cada ciclo de riquetsemia, ocorre emergência de A. marginale expressando variantes distintas de MSP2, as quais contém epitopos imunogênicos que induzem anticorpos específicos durante a infecção persistente da riquétsia (French et al. 1999) (Fig. 3). Acredita-se que essa variação antigênica é um mecanismo de evasão da resposta imune.

Os mecanismos de variação genética em msp2 estão sendo intensamente estudados. Brayton et al. (2001) demonstraram que pseudogenes das famílias msp2 e msp3 se recombinam no sítio de expressão funcional para gerar novas variantes antigênicas, sendo que a coordenação do processo de recombinação permite a essas duas famílias de genes agir sinergicamente na evasão da resposta imune do hospedeiro. No entanto, postula-se que este mecanismo não seja suficiente para gerar o número de variantes requerido para o estabelecimento de uma infecção persistente (Brayton et al. 2002). Recentemente, demonstrou-se que a recombinação de um pseudogene é seguida de um segundo nível de variação, no qual pequenos segmentos de pseudogenes se recombinam no sítio de expressão por conversão gênica (Brayton et al. 2002).

A inoculação de bovinos com membrana externa de $A$. marginale resultou em proteção de $70 \%$ dos bovinos, a qual correlacionou-se com títulos de anticorpos contra MSP2 (Tebele et al. 1991). A imunização de bovinos com MSP2 nativa induziu proteção contra desafio com isolado homólogo de $A$. marginale da Flórida e com isolado heterólogo de Washington, com grau de proteção variando de significativo atraso no início da riquetsemia até ausência completa da mesma (Palmer et al. 1988). Proteção total foi atingida com imuniza- 
ção de bovinos com membrana externa de $A$. marginale do isolado da Flórida, utilizando saponina como adjuvante, após desafio com isolado homólogo (Brown et al. 1998a). Esta proteção estava associada com o desenvolvimento de $\operatorname{IgG}_{2}$ principalmente contra MSP2 e com a produção de IFN-g por células T CD4+. Várias linhas de células T CD4+ derivadas dos animais imunizados reconheceram MSP2, e reagiram também com diferentes isolados de $A$. marginale, sugerindo que há epitopos T conservados entre isolados (Brown et al. 1998b). Recentemente, verificou-se que células T CD4 ${ }^{+}$específicas para MSP2 reconheceram epitopos comuns a vários isolados de $A$. marginale. Observou-se ainda que os epitopos conservados, localizados nas regiões $\mathrm{N}$ e $\mathrm{C}$ terminais, induziram a produção de altos níveis de IFN-g (Brown et al. 2001a).

Supõe-se que os linfócitos $\mathrm{T}$ específicos para epitopos altamente conservados da MSP2 possam ativar macrófagos e atuarem como células auxiliadoras para linfócitos B, estimulando respostas humorais primárias contra as distintas regiões variáveis daquela proteína, expostas na superfície dos corpúsculos iniciais a cada pique de riquetsemia (Brown et al. 2001a).

Estratégias para utilização da MSP2 como imunógeno devem incluir a identificação mais precisa dos epitopos $\mathrm{T}$ imunodominantes nessa proteína e para determinar quais seqüências podem servir como epitopos universais para moléculas do complexo de histocompatibilidade principal de bovinos (Brown et al. 2001a). Estratégias de imunomodulação da resposta imune celular para o padrão Th 1 também teriam impacto positivo, uma vez que este tipo de resposta é importante contra organismos intracelulares (Tuo et al. 2000). Nesse sentido, já se verificou que a citocina interleucina (IL)-12, utilizada como adjuvante para a MSP2, co-adsorvida com alúmen, estimulou respostas proliferativas de linfócitos $\mathrm{T}$ de bovinos imunizados, com aumento significativo da produção de IFNg e IL-2. Também estimulou níveis séricos elevados de IgG, principalmente $\operatorname{lgG}_{1}$ (Tuo et al. 2000).

\section{MSP3}

A MSP3 é uma proteína imunodominante em infecções natural e experimentais (Palmer et al. 1986b, McGuire et al. 1991). Altos níveis de anticorpos contra esta proteína foram detectados em soros de bovinos cerca de 30 dias após a infeç̧ão por $A$. marginale e em animais portadores por pelo menos cinco anos (Palmer et al. 1986b, McGuire et al. 1991).

A MSP3 nativa foi utilizada como antígeno para detecção de anticorpos em animais portadores, demonstrando alta sensibilidade (McGuire et al. 1991). No entanto, estudos posteriores revelaram que soros de animais infectados com Anaplasma ovis, Ehrlichia risticii e Ehrlichia ewingii reagiram com esse antígeno (Alleman \& Barbet 1996). Também se demonstrou que soros de bovinos infectados com isolados geograficamente distintos de $A$. marginale apresentaram variações na reação com MSP3 purificada do isolado da Flórida, caracterizando polimorfismo antigênico (Alleman \& Barbet 1996).

Os estudos que caracterizaram a MSP3 como polimórfica entre isolados foram corroborados pela análise dos genes que a codificam. Essa proteína é codificada por uma família multigênica. Utilizando o gene msp3-12 como sonda, foram identificadas cópias parcialmente homólogas nos genomas de três isolados de $A$. marginale, as quais estavam amplamente distribuídas no cromossomo (Alleman et al. 1997). A análise dos genes msp3-12, msp3-11 e msp3-19 demonstrou que há regiões conservadas e variáveis. Além disso, verificou-se que msp3 codifica blocos de aminoácidos relacionados com a família multigênica msp2 (Alleman et al. 1997).

Bovinos imunizados com MSP3 nativa apresentaram um retardo no surgimento da riquetsemia após o desafio (Palmer $\&$ McElwain 1995). Devido ao seu potencial como imunógeno, o papel das respostas celulares contra MSP3 foi estudado. Células mononucleares de sangue periférico de bovinos imunizados $\operatorname{com} A$. marginale responderam a MSP3, demonstrando que esta proteína contém epitopos T imunogênicos (Brown et al. 1998b). Linfócitos T CD4 ${ }^{+}$de bovinos imunizados com A. marginale, obtidos antes do desafio, responderam a MSP3, MSP2 ou ambos, em diversos isolados, demonstrando-se que há epitopos $\mathrm{T}$ comuns nessas duas proteínas, os quais são conservados. Todos os clones de células $\mathrm{T} \mathrm{CD} 4^{+}$produziram IFN-g e fator de necrose tumoral-a; a maioria co-expressou IL4 (Brown et al. 1998b).

\section{MSP4}

A MSP4 é uma proteína conservada entre diferentes isolados geográficos de $A$. marginale, incluindo os brasileiros (Palmer \& McGuire 1984, Oberle et al. 1993, Leal et al. 2000, Kano et al. 2002, Oliveira et al. 2003) presente na membrana interna e externa dessa riquétsia (Palmer \& McGuire 1984). Também está presente em $A$. centrale, mas está ausente em Anaplasma ovis (Oberle et al. 1993).

A MSP4 é codificada por gene de cópia única (Oberle et al. 1993), que apresenta homologia com o gene da proteína MAP1 de Cowdria ruminantium, também codificada por gene de cópia única (van Vliet et al. 1994). Esse gene apresenta ainda homologia com as famílias multigênicas que codificam as proteínas de $30 \mathrm{kDa}$ de E. canis e P28 de E. chaffeensis (Ohashi et al. 1998).

O potencial da MSP4 como imunógeno foi parcialmente analisado. Soros de bovinos imunizados com membrana externa de $A$. marginale e protegidos contra desafio com isolado virulento reconheceram a MSP4 (Oberle et al. 1993). A imunização de bovinos com MSP4 nativa induziu proteção contra desafio com isolado homólogo de $A$. marginale (Palmer $\&$ McElwain 1995). No entanto, até o momento, não existem informações sobre os epitopos responsáveis pela indução de uma resposta imune protetora nessa proteína.

\section{MSP5}

A MSP5 é uma proteína altamente conservada entre diferentes isolados de $A$. marginale, bem como em $A$. centrale e $A$. ovis (Visser et al. 1992). Ocorre nas formas monomérica, contendo pontes dissulfeto intramoleculares, e dimérica, apresentando pontes dissulfeto intermoleculares, na membrana de $A$. marginale (Vidotto et al. 1994).

O anticorpo monoclonal ANAF16C1 reconhece um epitopo imunodominante nessa proteína, o qual requer regiões $\mathrm{C}$ e $\mathrm{N}$ 
terminais da MSP5, indicando sua natureza conformacional (Munodzana et al. 1998). Devido às características de conservação do epitopo reconhecido por esse anticorpo entre as diferentes espécies e isolados de Anaplasma, o mesmo foi utilizado para o desenvolvimento de um ensaio de imunoadsorção enzimático (ELISA) competitivo, capaz de detectar anticorpos contra $A$. marginale e $A$. ovis com alta sensibilidade especificidade, inclusive em animais persistentemente infectados (Ndung'u et al. 1995, Knowles et al. 1996). Além disso, em animais infectados com $A$. marginale e $A$. ovis, esse epitopo induz altos títulos de anticorpos (Visser et al. 1992, Ndung'u et al. 1995, Knowles et al. 1996, Echaide et al. 1998).

Em bovinos, sabe-se que a imunização com membrana externa de $A$. marginale induz proteção contra desafio com isolado homólogo e heterólogo dessa riquétsia, a qual está correlacionada com os títulos de anticorpos contra as proteínas de membrana, incluindo a MSP5 (Tebele et al. 1991, Palmer et al. 1994b). No entanto, a imunização com MSP5 nativa não protegeu contra desafio com isolado homólogo de A. marginale (Palmer \& McElwain 1995).

\section{IMUNIZAÇÃO UTILIZANDO Anaplasma marginale PROVENIENTE DE CULTURA CELULAR}

Uma das alternativas para a imunização contra $A$. marginale é o cultivo in vitro dessa riquétsia, o qual constituiria uma alternativa econômica, segura e eficaz de produção de antígenos (Waghela et al. 2000). Cultivos de $A$. marginale foram feitos em diversos tipos de substrato. Em alguns deles, tais como células de medula óssea de coelho (Marble \& Hanks 1972), células de linfonodo de bovinos (Hidalgo 1975) e células de mosquito Aedes albopictus (Mazzola et al. 1979), não houve evidências conclusivas da multiplicação da riquétsia, embora a manutenção dos organismos tenha sido indicada por microscopia e/ou infecção de bovinos com material de cultura.

A multiplicação de $A$. marginale em cultura foi descrita em eritrócitos de bovinos e ovinos (Kessler \& Ristic 1979). Nesse sistema, uma cepa atenuada da riquétsia foi cultivada por 42 dias, apresentando um pique inicial de crescimento, seguido de um decréscimo gradual do percentual de eritrócitos infectados, com pequenos piques cíclicos.

Avanços significativos no cultivo de $A$. marginale em eritrócitos de bovinos foram alcançados pela adição de células endoteliais de bovinos, o que permitiu a manutenção da cultura com riquetsemia variando de 5 a $13 \%$ por 16 semanas (Waghela et al. 1997). A integridade da composição antigênica da riquétsia, cultivada nesse sistema, foi posteriormente avaliada por meio de dois anticorpos monoclonais, um contra MSP2 e outro contra uma proteína de $73 \mathrm{kDa}$, por imunofluorescência e Western blot (Waghela et al. 2000).

Apesar da possibilidade de cultivo de $A$. marginale por períodos prolongados em eritrócitos de bovinos, a utilização de organismos provenientes dessas culturas como imunógeno apresentam ainda algumas limitações. As vacinas derivadas de sangue requerem a utilização de animais livres de patógenos importantes doadores de eritrócitos. Outro incon- veniente é a dificuldade de purificação da riquétsia dos eritrócitos, a fim de evitar a indução de iso-anticorpos (Dennis et al. 1970).

Nesse sentido, um avanço considerável foi o cultivo de $A$. marginale em células de carrapato. Inicialmente, sangue de bovinos infectado com essa riquétsia foi inoculado em linhagem de célula proveniente de $D$. variabilis, resultando, no $20^{\circ}$ dia de cultivo, em um número de organismos semelhantes a Anaplasma pelo menos 10 vezes superior ao observado no $10^{\circ}$ dia (Samish et al. 1988).

A inoculação de $A$. marginale proveniente de intestino de carrapatos $D$. variabilis infectados resultou em culturas contínuas de $A$. marginale que se mantiveram por até 22 passagens por 11 meses (Hidalgo et al. 1989a). No entanto, tentativas de infecção de bovino com organismos cultivados dessa forma falharam (Hidalgo et al. 1989b).

Anaplasma marginale foi também cultivado em linhagem celular IDE8, derivada de embriões do carrapato Ixodes scapularis (Munderloh et al. 1996). Os organismos cultivados foram infectantes para bovinos e carrapatos (Munderloh et al. 1996, Blouin et al. 1998). As seis MSPs caracterizadas em A. marginale provenientes de eritrócitos de bovinos estavam conservadas nos organismos cultivados (isolado de Virgínia) (Barbet et al. 1999). A variabilidade do sítio de expressão genômica da MSP2 do isolado de Oklahoma transmitido de cultura in vitro para bovinos foi também analisada. Esse sítio apresentou-se conservado, exceto a seqüência que codifica a região hipervariável da MSP2 (Barbet et al. 2001).

Recentemente, $A$. marginale proveniente de cultivo em células IDE8, foi testado como imunógeno. Títulos máximos de anticorpos foram obtidos duas semanas após a última imunização e foram significativamente superiores aos obtidos em animais inoculados $\operatorname{com} A$. marginale proveniente de eritrócitos de bovinos infectados. Quanto às respostas específicas contra o complexo MSP1, os animais imunizados com organismos de cultura celular produziram anticorpos predominantemente contra MSP1b, enquanto aqueles inoculados com $A$. marginale proveniente de eritrócitos de bovinos infectados direcionaram a resposta principalmente contra MSP1a. Com relação à proteção, os animais imunizados com organismos de cultura celular não tiveram diferenças significativas com relação ao período pré-patente nem quanto ao percentual de eritrócitos infectados com $A$. marginale quando comparado ao grupo controle não imunizado, porém apresentaram uma significativa diferença na redução do volume globular e não apresentaram sinais clínicos de anaplasmose (Kocan et al. 2001).

Além da vantagem que a imunização com organismos provenientes de cultura de células de carrapato teria, em função da ausência de células e patógenos de bovinos (Kocan et al. 2001), diversos isolados de $A$. marginale poderiam ser propagados em cultura, ampliando o espectro de proteção contra a anaplasmose (Fuente et al. 2001c). No entanto, tais cultivos teriam que ser feitos em separado, uma vez que o cultivo de um genótipo de $A$. marginale exclui o crescimento de outro (Fuente et al. 2002b). 


\section{REFERÊNCIAS}

Alleman A.R. \& Barbet A.F. 1996. Evaluation of Anaplasma marginale major surface protein 3 (MSP3) as a diagnostic test antigen. J. Clin. Microbiol. 34:270-276.

Alleman A.R., Palmer G.H., McGuire T.C., McElwain T.F., Perryman L.E. \& Barbet A.F. 1997. Anaplasma marginale major surface protein 3 is encoded by a polymorphic, multigene family. Infect. Immun. 65:156-163.

Allred D.R., McGuire T.C., Palmer G.H., Leib S.R., Harkins T.M., McElwain T.F. \& Barbet A.F. 1990. Molecular basis for surface antigen size polymorphisms and conservation of a neutralization-sensitive epitope in Anaplasma marginale. Proc. Natl Acad. Sci. USA. 87:3220-3224.

Arulkanthan A., Brown W.C., McGuire T.C. \& Knowles D.P. 1999. Biased immunoglobulin G1 isotype responses induced in cattle with DNA expressing msp 1a of Anaplasma marginale. Infect. Immun. 67:3481-3287.

Barbet A.F. 1995. Recent developments in the molecular biology of anaplasmosis. Vet. Parasitol. 57:43-49.

Barbet A.F. \& Allred D.R. 1991. The msp 1 beta multigene family of Anaplasma marginale: nucleotide sequence analysis of an expressed copy. Infect. Immun. 59:971-976.

Barbet A.F., Palmer G.H., Myler P.J. \& McGuire T.C. 1987. Characterization of an immunoprotective protein complex of Anaplasma marginale by cloning and expression of the gene coding for polypeptide Am105L. Infect. Immun. 55:2428-2435.

Barbet A.F., Blentlinger R., Yi J., Lundgren A.M., Blouin E.F. \& Kocan K.M. 1999. Comparison of surface proteins of Anaplasma marginale grown in tick cell culture, tick salivary glands, and cattle. Infect. Immun. 67:102107.

Barbet A.F., Yi J., Lundgren A., McEwen B.R., Blouin E.F. \& Kocan K.M. 2001. Antigenic variation of Anaplasma marginale: major surface protein 2 diversity during cyclic transmission between ticks and cattle. Infect. Immun. 69:30573066.

Blouin E.F., Saliki J.T., Kocan K.M. \& Rodgers S.J. 1998. Evaluation of Anaplasma marginale from tick cell culture as an immunogen for cattle. Ann. N.Y. Acad. Sci. 849:253-258

Bowie M.V., Fuente J. de la, Kocan K.M., Blouin E.F. \& Barbet A.F. 2002. Conservation of major surface protein 1 genes of Anaplasma marginale during cyclic transmission between ticks and cattle. Gene 282:95-102.

Brayton K.A., Knowles D.P., McGuire T.C. \& Palmer G.H. 2001. Efficient use of a small genome to generate antigenic diversity in tick-borne ehrlichial pathogens. Proc. Natl Acad. Sci. USA. 98:4130-4135.

Brayton K.A., Palmer G.H., Lundgren A., Yi J. \& Barbet A.F. 2002. Antigenic variation of Anaplasma marginale msp2 occurs by combinatorial gene conversion. Mol. Microbiol. 43:1151-1159.

Brown W.C., Shkap V., Zhu D., McGuire T.C., Tuo W., McElwain T.F. \& Palmer G.H. 1998a. CD4 ${ }^{+}$T-lymphocyte and immunoglobulin G2 responses in calves immunized with Anaplasma marginale outer membranes and protected against homologous challenge. Infect. Immun. 66:5406-5413.

Brown W.C., Zhu D., Shkap V., McGuire T.C., Blouin E.F., Kocan K.M. \& Palmer G.H. 1998b. The repertoire of Anaplasma marginale antigens recognized by $\mathrm{CD}^{+}$T-lymphocyte clones from protectively immunized cattle is diverse and includes major surface protein 2 (MSP-2) and MSP-3. Infect. Immun. 66:5414-5422.

Brown W.C., McGuire T.C., Zhu D., Lewin H.A., Sosnow J. \& Palmer G.H. 2001a. Highly conserved regions of the immunodominant major surface protein 2 of the genogroup II ehrlichial pathogen Anaplasma marginale are rich in naturally derived $\mathrm{CD}^{+} \mathrm{T}$ lymphocyte epitopes that elicit strong recall responses. J. Immunol. 166:1114-1124.

Brown W.C., Palmer G.H., Lewin H.A. \& McGuire T.C. 2001b. CD4 ${ }^{+}$T lymphocytes from calves immunized with Anaplasma marginale major surface protein 1 (MSP1), a heteromeric complex of MSP1a and MSP1b, preferentially recognize the MSP1a carboxyl terminus that is conserved among strains. Infect. Immun. 69:6853-6862.

Camacho-Nuez. M, Lourdes Munoz M. de, Suarez C.E., McGuire T.C., Brown
W.C. \& Palmer G.H. 2000. Expression of polymorphic msp1b genes during acute Anaplasma marginale rickettsemia. Infect. Immun. 68:1946-1952.

Cantor G.H., Pontzer C.H. \& Palmer G.H. 1993. Opsonization of Anaplasma marginale mediated by bovine antibody against surface protein MSP-1. Vet. Immunol. Immunopathol. 37:343-350.

Daubenberger C.A., Taracha E.L., Gaidulis L., Davis W.C. \& McKeever D.J. 1999. Bovine gd T-cell responses to the intracellular protozoan parasite Theileria parva. Infect. Immun. 67:2241-2249.

Dennis R.A., O'Hara P.J., Young M.F. \& Dorris K.D. 1970. Neonatal immunohemolytic anemia and icterus of calves. J. Am. Vet. Med. Assoc. 156:1861-1869.

Dumler J.S., Barbet A.F., Bekker C.P., Dasch G.A., Palmer G.H., Ray S.C., Rikihisa Y. \& Rurangirwa F.R. 2001. Reorganization of genera in the families Rickettsiaceae and Anaplasmataceae in the order Rickettsiales: unification of some species of Ehrlichia with Anaplasma, Cowdria with Ehrlichia and Ehrlichia with Neorickettsia, descriptions of six new species combinations and designation of Ehrlichia equi and "HGE agent" as subjective synonyms of Ehrlichia phagocytophila. Int. J. Syst. Evol. Microbiol. 51:2145-2165.

Echaide S.T., Knowles D.P., McGuire T.C., Palmer G.H., Suarez C.E. \& McElwain T.F. 1998. Detection of cattle naturally infected with Anaplasma marginale in a region of endemicity by nested PCR and a competitive enzyme-linked immunosorbent assay using recombinant major surface protein 5 . J. Clin. Microbiol. 36:777-782.

Eriks I.S., Stiller D. \& Palmer G.H. 1993. Impact of persistent Anaplasma marginale rickettsemia on tick infection and transmission. J. Clin. Microbiol. 31:2091-2096.

Estes D.M., Closser N.M. \& Allen G.K. 1994. IFN-g stimulates IgG2 production from bovine B cells costimulated with anti-m and mitogen. Cell. Immunol. 154:287-295.

French D.M., Brown W.C. \& Palmer G.H. 1999. Emergence of Anaplasma marginale antigenic variants during persistent rickettsemia. Infect. Immun. 67:5834-5840

Fuente J. de la, Garcia-Garcia J.C., Blouin E.F. \& Kocan K.M. 2001a. Differential adhesion of major surface proteins $1 \mathrm{a}$ and $1 \mathrm{~b}$ of the ehrlichial cattle pathogen Anaplasma marginale to bovine erythrocytes and tick cells. Int. J. Parasitol. 31:145-153.

Fuente J. de la, Garcia-Garcia J.C., Blouin E.F., McEwen B.R., Clawson D. \& Kocan K.M. 2001b. Major surface protein 1a effects tick infection and transmission of Anaplasma marginale. Int. J. Parasitol. 31:1705-1714.

Fuente J. de la, Van Den Bussche R.A. \& Kocan K.M. 2001c. Molecular phylogeny and biogeography of North American isolates of Anaplasma marginale (Rickettsiaceae: Ehrlichiae). Vet. Parasitol. 97:65-76.

Fuente J. de la, Garcia-Garcia J.C., Blouin E.F., Saliki J.T. \& Kocan K.M. 2002a. Infection of tick cells and bovine erythrocytes with one genotype of the intracellular Ehrlichia Anaplasma marginale excludes infection with other genotypes. Clin. Diagn. Lab. Immunol. 9:658-668.

Fuente J. de la, Van Den Bussche R.A., Garcia-Garcia J.C., Rodriguez S.D., Garcia M.A., Guglielmone A.A., Mangold A.J., Friche Passos L.M., Barbosa Ribeiro M.F., Blouin E.F. \& Kocan K.M. 2002b. Phylogeography of New World isolates of Anaplasma marginale based on major surface protein sequences. Vet. Microbiol. 88:275-285.

Gale K.R., Leatch G., Gartside M. \& Dimmock C.M. 1992. Anaplasma marginale: failure of sera from immune cattle to confer protection in passive-transfer experiments. Parasitol. Res. 78:410-415.

Gale K.R., Leatch G., Dimmock C.M. \& Wood P.R. 1997. Anaplasma marginale: effect of the treatment of cattle with an interferon-g neutralizing monoclonal antibody or the nitric oxide synthetase inhibitor aminoguanidine on the course of infection. Parasite Immunol. 19:411-417.

Hidalgo R.J. 1975. Propagation of Anaplasma marginale in bovine lymph node cell culture. Am. J. Vet. Res. 36:635-640.

Hidalgo R.J., Jones E.W., Brown J.E. \& Ainsworth A.J. 1989a. Anaplasma marginale in tick cell culture. Am. J. Vet. Res. 50:2028-2032.

Hidalgo R.J., Palmer G.H., Jones E.W., Brown J.E. \& Ainsworth A.J. 1989b. 
Infectivity and antigenicity of Anaplasma marginale from tick cell culture. Am. J. Vet. Res. 50:2033-2036.

Jones W.E., Kliewer I.O., Norman B.B. \& Brock W.E. 1968. Anaplasma marginale infection in young and aged cattle. Am. J. Vet. Res. 29:535-544.

Kano F.S., Vidotto O., Pacheco R.C. \& Vidotto M.C. 2002. Antigenic characterization of Anaplasma marginale isolates from different regions of Brazil. Vet. Microbiol. 87:131-138.

Kessler R.H. \& Ristic M. 1979. In vitro cultivation of Anaplasma marginale: invasion of and development in noninfected erythrocytes. Am. J. Vet. Res. 40:1774-1776.

Kessler R.H. \& Schenk M.A.M. 1998. Carrapato, Tristeza Parasitária e Tripanossomose dos Bovinos. Embrapa Gado de Corte, Campo Grande, MS. $115 p$.

Knowles D., Echaide S.T. de, Palmer G., McGuire T., Stiller D. \& McElwain T. 1996. Antibody against an Anaplasma marginale MSP5 epitope common to tick and erythrocyte stages identifies persistently infected cattle. J. Clin. Microbiol. 34:2225-2230.

Kocan K.M., Halbur T., Blouin E.F., Onet V., Fuente J. de la, Garcia-Garcia J.C. \& Saliki J.T. 2001. Immunization of cattle with Anaplasma marginale derived from tick cell culture. Vet. Parasitol. 102:151-161.

Leal M., Noda A., Reyna-Bello A., Casas B., Precigout E., Aso P.M., Gorenflot A. \& Gonzatti M.I. 2000. Identification and characterization of corpuscular, soluble and secreted antigens of a Venezuelan isolate of Anaplasma marginale. Vet. Parasitol. 94:1-15.

Lew A.E., Bock R.E., Minchin C.M. \& Masaka S. 2002. A msp1a polymerase chain reaction assay for specific detection and differentiation of Anaplasma marginale isolates. Vet. Microbiol. 86:325-335.

Madruga C.R., Gomes A., Schenk M.A.M., Kessler R.H., Gratão, G., Gales M.E., Schenk, J.A.P., Andreasi, M., Bianchin I. \& Miguita M. 1984. Etiologia de algumas doenças de bezerros de corte no Estado de Mato Grosso do Sul. Circular Técnica 15, Embrapa-CNPGC, Campo Grande, MS. 27p.

Madruga C.R., Kessler R.H., Gomes A., Schenk M.A.M. \& Andrade D.F. 1985. Níveis de anticorpos e parasitemia de $A$. marginale em área enzoótica, nos bezerros da raça Nelore, Ibagé e cruzamentos de Nelore. Pesq. Agropec. Bras. 20:135-142.

Marble D.W. \& Hanks M.A. 1972. A tissue culture method for Anaplasma marginale. Cornell Vet. 62:196-205.

Mazzola V., Amerault T.E. \& Roby T.O. 1979. Electron microscope studies of Anaplasma marginale in an Aedes albopictus culture system. Am. J. Vet. Res. 40:1812-1815.

McBride J.W., Yu X.J. \& Walker D.H. 2000. Glycosylation of homologous immunodominant proteins of Ehrlichia chaffeensis and Ehrlichia canis. Infect. Immun. 68:13-18.

McGarey D.J. \& Allred D.R. 1994. Characterization of hemagglutinating components on the Anaplasma marginale initial body surface and identification of possible adhesins. Infect. Immun. 62:4587-4593.

McGarey D.J., Barbet A.F., Palmer G.H., McGuire T.C. \& Allred D.R. 1994. Putative adhesins of Anaplasma marginale: major surface polypeptides 1a and $1 \mathrm{~b}$. Infect. Immun. 62:4594-4601.

McGuire T.C., Musoke A.J. \& Kurtti T. 1979. Functional properties of bovine $\operatorname{IgG}_{1}$ and $\operatorname{IgG}_{2}$ : interaction with complement, macrophages, neutrophils and skin. Immunology 38:249-256.

McGuire T.C., Palmer G.H., Goff W.L., Johnson M.I. \& Davis W.C. 1984. Common and isolate-restricted antigens of Anaplasma marginale detected with monoclonal antibodies. Infect. Immun. 45:697-700.

McGuire T.C., Davis W.C., Brassfield A.L., McElwain T.F. \& Palmer G.H. 1991. Identification of Anaplasma marginale long-term carrier cattle by detection of serum antibody to isolated MSP-3. J. Clin. Microbiol. 29:788-793.

Munderloh U.G., Blouin E.F., Kocan K.M., Ge N.L., Edwards W.L. \& Kurtti T.J. 1996. Establishment of the tick (Acari: Ixodidae)-borne cattle pathogen Anaplasma marginale (Rickettsiales: Anaplasmataceae) in tick cell culture. J. Med. Entomol. 33:656-664.

Munodzana D., McElwain T.F., Knowles D.P. \& Palmer G.H. 1998. Conforma- tional dependence of Anaplasma marginale major surface protein 5 surfaceexposed B-cell epitopes. Infect. Immun. 66:2619-2624.

Ndung'u L.W., Aguirre C., Rurangirwa F.R., McElwain T.F., McGuire T.C., Knowles D.P. \& Palmer G.H. 1995. Detection of Anaplasma ovis infection in goats by major surface protein 5 competitive inhibition enzyme-linked immunosorbent assay. J. Clin. Microbiol. 33:675-679.

Oberle S.M., Palmer G.H., Barbet A.F. \& McGuire T.C. 1988. Molecular size variations in an immunoprotective protein complex among isolates of Anaplasma marginale. Infect. Immun. 56:1567-1573.

Oberle S.M., Palmer G.H. \& Barbet A.F. 1993. Expression and immune recognition of the conserved MSP4 outer membrane protein of Anaplasma marginale. Infect. Immun. 61:5245-5251.

Ohashi N., Unver A., Zhi N. \& Rikihisa Y. 1998. Cloning and characterization of multigenes encoding the immunodominant 30-kilodalton major outer membrane proteins of Ehrlichia canis and application of the recombinant protein for serodiagnosis. J. Clin. Microbiol. 36:2671-2680.

Oliveira J.B., Madruga C.R., Schenk M.A.M, Kessler R.H., Miguita M. \& Araújo F.R. 2003. Antigenic characterization of four Brazilian isolates of Anaplasma marginale Rickettsiaceae: Ehrlichiae. Mem. Inst. Oswaldo Cruz 98. (Em publicação)

Palmer G.H. 1989. Anaplasma vaccines, p.1-29. In: Wright I.G. (ed.) Veterinary Protozoan and Hemoparasite Vaccines. CRC Press, Boca Raton, Florida.

Palmer G.H. \& McElwain T.F. 1995. Molecular basis for vaccine development against anaplasmosis and babesiosis. Vet. Parasitol. 57:233-253.

Palmer G.H. \& McGuire T.C. 1984. Immune serum against Anaplasma marginale initial bodies neutralizes infectivity for cattle. J. Immunol. 133:1010-1015.

Palmer G.H., Barbet A.F., Davis W.C. \& McGuire T.C. 1986a. Immunization with an isolate-common surface protein protects cattle against anaplasmosis. Science 231:1299-1302.

Palmer G.H., Barbet A.F., Kuttler K.L. \& McGuire T.C. 1986b. Detection of an Anaplasma marginale common surface protein present in all stages of infection. J. Clin. Microbiol. 23:1078-1083.

Palmer G.H., Waghela S.D., Barbet A.F., Davis W.C. \& McGuire T.C. 1987. Characterization of a neutralization-sensitive epitope on the Am 105 surface protein of Anaplasma marginale. Int. J. Parasitol. 17:1279-1285.

Palmer G.H., Oberle S.M., Barbet A.F., Goff W.L., Davis W.C. \& McGuire T.C. 1988. Immunization of cattle with a 36-kilodalton surface protein induces protection against homologous and heterologous Anaplasma marginale challenge. Infect. Immun. 56:1526-1531.

Palmer G.H., Barbet A.F., Cantor G.H. \& McGuire T.C. 1989. Immunization of cattle with the MSP-1 surface protein complex induces protection against a structurally variant Anaplasma marginale isolate. Infect. Immun. 57:36663669.

Palmer G.H., Eid G., Barbet A.F., McGuire T.C. \& McElwain T.F. 1994a. The immunoprotective Anaplasma marginale major surface protein 2 is encoded by a polymorphic multigene family. Infect. Immun. 62:3808-3816.

Palmer G.H., Munodzana D., Tebele N., Ushe T. \& McElwain T.F. 1994b. Heterologous strain challenge of cattle immunized with Anaplasma marginale outer membranes. Vet. Immunol. Immunopathol. 42:265-273.

Palmer G.H., Rurangirwa F.R., Kocan K.M. \& Brown W.C. 1999. Molecular basis for vaccine development against the ehrlichial pathogen Anaplasma marginale. Parasitol. Today 15:281-286.

Ristic M. 1979. Bovine anaplasmosis with emphasis on immune responses and protection (Summary), p.22. In: Annals Symposium on the Use of Isotopes for Research and Control Vectors of Animal Diseases Host Pathogen Relationships and Enviromental Impact of Control Procedures. FAO, Viena, Italy.

Rogers R.J., Dimmock C.K., Vos A.J. de \& Rodwell B.J. 1988. Bovine leucosis virus contamination of a vaccine produced in vivo against bovine babesiosis and anaplasmosis. Aust. Vet. J. 65: 285-287.

Samish M., Pipano E. \& Hana B. 1988. Cultivation of Anaplasma marginale from cattle in a Dermacentor cell line. Am. J. Vet. Res. 49:254-256.

Storey J.R., Doros-Richert L.A., Gingrich-Baker C., Munroe K., Mather T.N., 
Coughlin R.T., Beltz G.A. \& Murphy C.I. 1998. Molecular cloning and sequencing of three granulocytic Ehrlichia genes encoding high-molecularweight immunoreactive proteins. Infect. Immun. 66:1356-1363.

Tebele N. \& Palmer G.H. 1991. Crossprotective immunity between the Florida and a Zimbabwe stock of Anaplasma marginale. Trop. Anim. Health Prod. 23:197-202.

Tebele N., McGuire T.C. \& Palmer G.H. 1991. Induction of protective immunity by using Anaplasma marginale initial body membranes. Infect. Immun. 59:3199-3204

Tuo W., Palmer G.H., McGuire T.C., Zhu D. \& Brown W.C. 2000. Interleukin-12 as an adjuvant promotes immunoglobulin $\mathrm{G}$ and type 1 cytokine recall responses to major surface protein 2 of the ehrlichial pathogen Anaplasma marginale. Infect. Immun. 68:270-280.

Valdez R.A., McGuire T.C., Brown W.C., Davis W.C., Jordan J.M. \& Knowles D.P. 2002. Selective in vivo depletion of CD4(+) T lymphocytes with anti-CD4 monoclonal antibody during acute infection of calves with Anaplasma marginale. Clin. Diagn. Lab. Immunol. 9:417-424.

Vidotto M.C., McGuire T.C., McElwain T.F., Palmer G.H. \& Knowles D.P. Jr. 1994. Intermolecular relationships of major surface proteins of Anaplasma marginale. Infect. Immun. 62:2940-2946.

Viseshakul N., Kamper S., Bowie M.V. \& Barbet A.F. 2000. Sequence and expression analysis of a surface antigen gene family of the rickettsia Anaplasma marginale. Gene 253:45-53.

Visser E.S., McGuire T.C., Palmer G.H., Davis W.C., Shkap V., Pipano E. \& Knowles D.P. Jr. 1992. The Anaplasma marginale msp5 gene encodes a 19- kilodalton protein conserved in all recognized Anaplasma species. Infect. Immun. 60:5139-5144.

Vliet A.H. van, Jongejan F., Kleef M. van \& Zeijst B.A. van der 1994. Molecular cloning, sequence analysis, and expression of the gene encoding the immunodominant 32-kilodalton protein of Cowdria ruminantium. Infect. Immun. 62:1451-1456.

Waghela S.D., Cruz D., Droleskey R.E., DeLoach J.R. \& Wagner G.G. 1997. In vitro cultivation of Anaplasma marginale in bovine erythrocytes co-cultured with endothelial cells. Vet. Parasitol. 73:43-52.

Waghela S.D., Melendy D., Cruz D. \& Wagner G.G. 2000. Antigenic analysis of Anaplasma marginale grown in bovine erythrocytes co-cultured with bovine endothelial cells. Vet. Parasitol. 94:133-139.

Wyatt C.R., Madruga C., Cluff C., Parish S., Hamilton M.J., Goff W. \& Davis W.C. 1994. Differential distribution of gd T-cell receptor lymphocyte subpopulations in blood and spleen of young and adult cattle. Vet. Immunol. Immunopathol. 40:187-199.

Yu X.J., Crocquet-Valdes P. \& Walker D.H. 1997. Cloning and sequencing of the gene for a 120-kDa immunodominant protein of Ehrlichia chaffeensis. Gene 184:149-154.

Yu X.J., McBride J.W., Diaz C.M. \& Walker D.H. 2000. Molecular cloning and characterization of the 120-kilodalton protein gene of Ehrlichia canis and application of the recombinant 120 -kilodalton protein for serodiagnosis of canine ehrlichiosis. J. Clin. Microbiol. 38:369-374.

Zaugg J.L., Stiller D., Coan M.E. \& Lincoln S.D. 1986. Transmission of Anaplasma marginale Theiler by males of Dermacentor andersoni Stiles fed on an Idaho field-infected, chronic carrier cow. Am. J. Vet. Res. 47:2269-2271. 